\title{
Hipocondria: uma falha no silencio dos órgãos ${ }^{1}$
}

\author{
Eliana Rache ${ }^{2}$
}

Tendo em vista a proposta da mesa de focar o mal-estar na cultura e suas expressões na Clínica da psicossomática, a figura da hipocondria ${ }^{3}$ escolhida para tal, não só faz parte deste nosso momento atual como sempre inundou com sua força enigmática séculos afora mostrando o quanto somos assaltados em nossas entranhas por este mistério da fragilidade do corpo traduzido em doença e morte.

O grito de dor e o pedido de ajuda do hipocondríaco vem questionando não só médicos como religiosos e filósofos há muitos séculos à despeito de minguados resultados no ato da cura. Nesta repetição de insucessos, impõe-se um denominador comum que se apresenta a todos esses profissionais da cura em contato com seu "doente hipocondríaco": um profundo sabor amargo de incompetência por não ter conseguido ajudar seu paciente.

Compreender o hipocondríaco não é fácil. Uma primeira questão óbvia é que dificilmente se dirigem ao consultório do psicanalista por entenderem que o que lhes afeta é algo da ordem do físico. São os consultórios médicos que os acolhe e que em não sabendo como proceder nessa cura, fracassam. O hipocondríaco vai num caminho sem fim de médico em médico para em vão encontrar sua cura.

Lanço uma primeira conjectura de que essa ronda sem fim pelos médicos faz parte de sua sintomatologia: de ser ele o único dono de sua doença como também o dono irrestrito do órgão doente.

\footnotetext{
1 Este trabalho foi apresentado na mesa "Hipocondria e psicossomática: desconcertos do corpo" com Maria Helena Fernandes no eixo "Psicanálise e suas clinicas" no I Simpósio Bienal "O mesmo, o outro: Psicanálise em movimento" da Sociedade Brasileira de Psicanálise de São Paulo.

2 Analista Didata da Sociedade Brasileira de Psicanálise de São Paulo, membro da École de Psychosomatique de Paris e doutora pelo Núcleo de Psicanálise da PUC-SP.

${ }^{3}$ Upo chondos "abaixo, atrás, da cartilagem das costelas". Na antiguidade, a hipocondria remetia a um órgão interno escondido entre o ventre e o peito, sítio dos humores. Não seria já uma alusão a um invisível corporal com sua exigência de representação? (2002, p.111)
} 
Desde muito cedo, Freud em Estudos sobre Histeria já viu no hipocondríaco alguém engajado num esforço insuperável para convencer seu interlocutor da qualidade e intensidade de suas dores: "Ele pensa verdadeiramente que a língua é pobre demais para lhe permitir pintar suas sensações; suas sensações são algo único, jamais visto, que não conseguiria descrever perfeitamente"(Freud-1895)

Dentro do cenário analítico Freud nunca deixou de estar às voltas com a hipocondria. Em 1893 classifica - a como um dos sintomas crônicos da neurose de angústia, mais tarde 1898 aloca-a como uma das duas neuroses atuais que incluía também a neurastenia. Numa carta à Ferenczi diz: "Sempre senti que a obscuridade na questão da hipocondria era uma lacuna desagradável da nossa teorização”.

Entretanto Freud nunca vai abandonar a ideia da participação do núcleo hipocondríaco em qualquer organização psicopatológica. (neurótica ou psicótica).

Numa linguagem do senso comum esses hipocondríacos são os que são chamados de doentes imaginários, aliás, imortalizados na peça teatral de Molière, "O Doente Imaginário"onde o médico Toinette procura a todo custo a localização da doença de seu paciente e assim confirmar as leis da hidráulica recém descobertas(século XV1l), atribuídas agora ao corpo-máquina de seu paciente desconcertado. Mal vistos, desconsiderados, os hipocondríacos muitas vezes confundidos com os histéricos em seu aspecto de inacessibilidade que causa irritação aos que deles se ocupam, levam mais tempo a serem vistos a olho nu do que os histéricos. A questão é justamente esta- eles só devem ser vistos a olho nu por que não tem nada que os empreste dimensionalidades a serem descobertas- tudo está à descoberto.Os histéricos não, logo fazem tombar diante dos médicos suas seduções convidando-os à buscá-los nas terras das "Mil e uma noites".

Se ambas tanto a histeria como a hipocondria aludem ao corpo doente, como diferenciálas? Lembremos que hoje a histeria não se mostra com as grandes encenações corporais como no tempo de Freud, elas se apresentam como dor. A diferença é delicada e poderemos encontrá-la de acordo com o funcionamento do eu. Se o material apresentado contiver alguma representação simbólica estamos falando de uma histérica, ao passo que no hipocondríaco o órgão emitirá uma mensagem de sofrimento sem nenhum conteúdo simbólico. A metapsicologia nos diz que em suas representações de 
palavra superinvestidas, o hipoconcondríaco revela sua pobreza, sua superficialidade na falta do uso de suas representações coisa. Situação que se mostra bastante diferente na histeria cujas representações coisa fracamente investidas, são ao contrário atuadas.

Fiz um caminho através de leitura e da clínica para compreender melhor não só o funcionamento clínico da hipocondria mas também sua gênese.

Para tal valho-me de dois pilares do conhecimento psicanalítico: a conceituação de masoquismo primário muito usado pela Escola de Psicossomática de Paris e a noção de simbolização primária, trabalho desenvolvido por Roussillon. Ambos arcabouços teóricos serviram-me de inspiração para tentar construir um caminho próprio de conhecimento.

O título de meu trabalho já é em si um convite para entrarmos no tema da hipocondria: uma falha no silencio dos órgãos. Assim diz M. Fain (1990) em seu trabalho "À respeito da hipocondria” " indaga: Do que é feito o silencio do corpo?” Teremos apenas que ter vivido uma parada cardíaca depois de uma série de extra-sístoles para saber que o silencio do corpo é feito de uma percepção contínua de impressões asseguradoras. Continua Fain: "Já se inscreve a hipótese que a sensação hipocondríaca será, de uma maneira ou de outra, uma falha no seio dessas percepções reasseguradoras, reação que visa sem dúvida combater sem sucesso a angustia ligada a essa percepção de uma falta.

Fain como toda a Escola de Paris enfatizam a noção de relação de objeto e assim na citação a seguir somos introduzidos aos tempos dos primórdios dos relacionamentos infantis. Diz ele: "o silencio reasssegurador do corpo é o herdeiro direto do enquadre suficientemente bom da infância que em silencio e ternamente asseguraria um bem estar à criança sem danificar sua potencialidade de desenvolvimento."

As preocupações relativas ao corpo definem a hipocondria. Segundo Freud elas aparecem como "sensações corporais penosas e dolorosas" (1914) e são acompanhadas pela retirada da libido dos objetos do mundo externo para se concentrarem sobre o eu e o órgão que o ocupa. Temos um corpo ou órgão que contem a dor só que não necessariamente existe uma lesão tão clara corporal, entretanto a angustia hipocondríaca 
com seu alarido queixoso toma conta e nos tira visibilidade de acompanhar o trajeto da própria dor algumas vezes, outras vezes de como tecer as ligações entre o órgão e a angustia hipocondríaca. Esta configuração da hipocondria levou a A.Jeanneau (2002) comentar: “ Um pensamento que não pode nada se obstina a perguntar à um corpo que não sabe nada". Trata-se para este autor de uma "inadequação do registro mental a seu objeto somático”.

Voltando a procurar saber o que comprometeu o silencioso bom funcionamento do corpo, podemos perguntar como teria sido este corpo antes dessa irrupção dolorosa e sonora?

De forma muito breve lembremos que Freud consegue através do conceito de pulsão (1915) e de sua representancia, estabelecer os laços entre somático e psíquico como processo histórico de construção do corpo no psiquismo. A dor desempenha papel preponderante nessa psiquização do corpo ao interferir no sistema prazer-desprazer através da economia do funcionamento do masoquismo primário.

Sua inflexão sobre o investimento do desprazer relativo à alucinação da satisfação primária deverá ser suficiente para permitir a passagem do princípio do prazer ao da realidade. No entanto a hipocondria mostra que é importante diferenciar desprazer de dor. Assim a angustia hipocondríaca poderá ser pensada como a expressão insuficiente do investimento de desprazer, que impede a organização de um adiamento de satisfação, advindo então, o superinvestimento da dor em sua dimensão a-histórica. Esta conceituação do funcionamento do masoquismo primário na constituição do psiquismo pareceu-me interessante para figurarmos a compreensão da dor no corpo e sua angustia que se espalha pela alma. Entretanto é a investigação das relações primordias entre a criança e o ambiente que traz num zoom esse tipo de patologia narcísica em geral e em específico no caso da hipocondria.

Nos adentramos dentro das alcovas dos inícios do "pequeno homem”através de um dado trazido pela clínica dos hipocondriacos plasmada em sua linguagem: pobre, tosca até mesmo infantil. Indagamo-nos como as representações de palavras circulam à despeito da pobreza das representações coisa. Este déficit no trabalho das representações coisa nos indica que a origem da dificuldade é na transformação dos 
traços perceptivos em representações coisa. Penso imediatamente no trabalho profícuo desenvolvido por RR nesta área da constituição do psiquismo na qual desenvolve o trabalho que chama de simbolização primária e que engloba as transformações dos traços perceptivos em representações coisa. Penso que a angustia hipocondríaca poderia estar ligada à manifestação alucinatória de algum traço perceptivo que não foi traduzido em representação coisa e, portanto não passou a ser uma representação psíquica desejável. O trabalho ficou pela metade deixando-se capturar através da modestia de suas palavras e da acusação ao corpo como vilão de todos os males. O destino é sábio, pois o próprio corpo acusado/acusador se expõe novamente em seu desatino através de representações fracas coloridas por queixas, por angustia e até mesmo por uma atenção em si mesmo desmedida.

A experiência clínica tem mostrado que a falta disparadora está em tempos primevos, ligada a um objeto cuja perda é negada. O que teria acontecido nesta ligação do bebê com este outro - o indispensável-nebenmensch? RR mostra-nos um caminho interessante para entender o que acontece com a perda no caso do melancólico. Vou me permitir ir pela mesma trilha que ele foi para pensarmos o caso do hipocondríaco. Fala RR: o melancólico tem uma grande decepção ao não receber do objeto- mãe o que ele imagina receber. Tenta outras vezes sem sucesso até essa experiência tornar-se traumática. Como solução ao desamparo do qual o bebê se sente tomado incorpora o outro por inteiro por ser isso melhor que nada. O objeto dentro deste eu incipiente assume o lugar de um "incorporat" que nunca chega fazer parte deste eu como uma "apropriação". ??? Tem lugar então as acusações do objeto contra o usurpador. No caso do hipocondríaco não teria havido um desinvestimento, um abandono por parte da mãe sobre o psiquismo corpo incipiente cujo efeito deletério recai não sobre o eu como no melancólico, mas sim sobre o corpo do infans. (zonas “isolats”). O dano será maior dependendo da área do eu deste corpomente em formação que foi atingida, visto que a hipocondria pode ser o presságio de uma psicose. Mas são conhecidos os casos onde clivagens mais brandas no eu se apresentam compondo um quadro tranqüilo de silencio dos órgãos obtido através de ligações não simbólicas até acontecer algum disparador que ponha em marcha o grito de dor do hipocondríaco. Pode-se pensar em clivagens do eu mais amenas no hipocondríaco como também nas mais rígidas e mais graves quanto à saúde do indivíduo que vai da angustia hipocondríaca, à convicção e finalmente ao delírio hipocondríaco. Claramente pode-se conjecturar que nas primeiras relações do 
hipocondríaco faltou por parte do objeto-mãe o que RR chama de compartilhamento estésico homosexual em duplo: as ecoizações através do trabalho em espelho e as harmonizações afetivas entre mãe e criança. Esse conhecimento advém de trabalhos dedicados a $1^{\mathrm{a}}$ infância onde foram resgatadas a presença do outro para servir de suporte a este tipo de trabalho, simbolização em presença, que tem que ser compartilhado inicialmente para se inscrever, ser integrado e apropriado pelo sujeito para se tornar processo de simbolização útil quando se fizer necessário, do contrário, desembocará nas formas de compulsão a repetição. É nesse embalo com o objeto primário (mãe) presente, que vão ocorrendo a apresentação dos potenciais do bebê a serem atualizados pela força simbolizante da mãe seja como continente, seja em sua função reflexiva de espelho, diria a Escola de Paris em sua função de para excitação. Freud ainda nos lembra que nesta seiva criadora da ação da mãe sobre o complexo perceptivo, como ele chama, nesse momento presente se divide em seus 2 constituintes: o primeiro mobilizado pelas diferenças vai estar na base do julgamento e o outro baseado nas semelhanças irão constituir identificações.

O trabalho de redimensionar as pesquisas e colocá-las à disposição de nosso conhecimento como teorias servem quando extraídas do trabalho do clínico vivo e atento em seu fazer diário. Empresto da clínica de Georges Pragier um caso interessante de um Sr. Ali, tunisiano de 35 anos, que apesar de falar o Frances só se expressa por mímicas e gestos apontando para representar o lugar de suas dores. Quando consegue falar aponta para sua barriga e diz: “... é sempre isso... é sempre ali que começa..” Pragier continua nos relatando que no limite de sua catatonia, Sr. Ali, protegendo sua barriga com as mãos, diz: “..é aí.. é sempre no mesmo lugar ..”. E Pragier certeiro se pergunta:... mas aí aonde? No não figurável? No não representável? No fantástico? Com certeza, não no fantasmático. Pragier levanta uma hipótese do quadro hipocondríaco de Sr. Ali: ele não se encontrava apto a encontrar as identificações histéricas precoces imprescindíveis para essa primeira estruturação do infans. Diz Pragier, que parece que a instalação dessas identificações histéricas de base é que permitem o silencio do corpo. Deste modo, a sensação hipocondríaca revelaria uma falha desta continuidade muda sobre a qual se efetua o trabalho analítico. Estamos aqui diante de um caso grave de hipocondria de acordo com o gradiente ao qual me referi mais acima no texto. 
Agora da minha clinica, trago um caso leve de alucinação hipocondríaca, numa paciente muito jovem de seus 20 e poucos anos. Ela não é minha paciente e sim sua mãe. O ensaio que faço é que a partir da mãe, nesta perspectiva o objeto primário, é possível recuperar a ação danosa de excesso em seu bebê prematuro, cuja prematuridade continua ser vivida pela mãe em comportamentos atuais de sua filha. O marido sempre viajou devido a seus negócios longe de casa. Mas de fato ele não fazia falta. Logo a mãe transforma seus dois filhos em seus dois espelhos narcísicos: o menino era seu galã e sua filha era ela mesma fazendo reviver o sonho do hipocondríaco da união primeva nunca desmanchada. Sra. A minha paciente conta que sua filha sempre tivera dificuldades maior do que os outros para tudo, o que exigia dela maior atenção e proximidade junto à filha. Até onde pude acompanhar, a filha de Sra. A teve alguns episódios que considero de angustias hipocondrias. Depois de um tombo cujo saldo foi algum problema no joelho, nunca mais deixou de conservar esse joelho como um talismã da dor. Nenhum médico até hoje conseguiu consertar sua dor no joelho o qual se presta a recriminações torturantes à mãe.Duas cirurgias foram realizadas sem nenhum sucesso e o joelho lá está para dizer que algo faltou e vai mal. Recentemente outro local passou a ocupar sua atenção, desta vez às vésperas de assumir um trabalho de maior responsabilidade surge uma dor "infinita" junto a região pubiana que a impede de andar. Levada ao médico a dor recebe o nome de "pubeíte" parece que na falta de palavra melhor. O caso desta moça ao ser apresentado numa mesa redonda de casos clínicos me chama atenção pelos dizeres bombásticos do terapeuta: "O traço principal nesta paciente é a incapacidade de simbolizar, parece que as palavras não tem profundidade".

Em silencio, atrevi-me a arriscar o diagnóstico de angustia hipocondríaca.

Pode ser um bom prognóstico e entrar numa condição mencionada por A.Gibeault de "solução hipocondríaca", na qual a expressão de angustia pode recuperar alguma ligação perdida e ir fazendo restituições e religando aspectos psíquicos que tinham sido desligados. Se pensarmos em termos terapêuticos também podemos ajudar muitos desses casos lembrando que o paciente sempre guarda no recôndito de sua cabeça liames recuperáveis para serem retramados.

RR continua a contar-nos como vai se esboçando a simbolização primária: segue a idéia original de Winnicott que simbolizamos em presença, muito diferente da concepção habitualmente aceita de que é sobre a ausência que o símbolo se cria. Esse 
conhecimento advém de trabalhos dedicados a $1^{\text {a }}$ infância onde resgatamos a presença do outro para servir de suporte a este tipo de simbolização em presença que tem que ser compartilhado inicialmente para se inscrever, ser integrado e apropriado pelo sujeito para se tornar processo de simbolização útil quando se fizer necessário, do contrário, desembocará nas formas de compulsão a repetição. É nesse embalo com o objeto primário (mãe) presente, que vão ocorrendo a apresentação dos potenciais do bebê a serem atualizados pela força simbolizante da mãe seja como continente, seja em sua função reflexiva de espelho. Mas tão logo o bebê não tenha mais o acoplamento inicial tão perfeito com a mãe, ele vai sendo apresentado a outros objetos que passam a lhe interessar no ambiente. Esses outros objetos, outros mediadores, objetos inanimados, apresentam uma característica a partir de sua própria natureza, que é de dar forma ao que devem conter. Em outras palavras, quando há a projeção da matéria prima psíquica sobre eles, ocorre uma transferência que transforma o enigmático e imaterial das experiências psíquicas em perceptível, materializável e sensível. Seja, o desprazer não consegue conter o que lhe está traumatizando ( não tem libido que o ajude para isso) e

sobrevem a dor, em "uma dimensão a - histórica."(Sd. M.Aisenstein p.105-A Hipocondria). O tempo para agüentar o desprazer não chega a ser suficiente sobrevindo a dor.

\section{Referências}

AISENSTEIN, M. FINE, A e PRAGIER, G. (2002). Hipocondria. Editora Escuta, São Paulo.

FAIN, M. (2010). À propos de l'hypocondrie. Revue française de Psychosomatique, n. 37.

FERRANT, A. (2018) La portance de l'autoèrotisme. Revue française de Psychanalise, 2018/3, vol 82 .

FAIN, M. (2010). À propos de l'hypocondrie. Revue française de Psychosomatique, n. 37.

FREDU S. (1923) O ego e o id. Edição Standard Brasileira de Obras Psicológicas

Completas de Sigmund Freud. Rio de Janeiro: Imago, 1976. v. XIX, p. 13-83. 
(1895) Estudos sobre a histeria. Edição Standard Brasileira de Obras Psicológicas Completas de Sigmund Freud. Rio de Janeiro: Imago, 1974. v. II, p. 13-39.

(1920) Além do princípio do prazer.Edição Standard Brasileira de Obras Psicológicas Completas de Sigmund Freud. Rio de Janeiro: Imago, 1976. v. XVIII, p. 17-85.

(1937) Construções em análise.Edição Standard Brasileira de Obras Psicológicas Completas de Sigmund Freud. Rio de Janeiro: Imago, 1976. v. XXIII, p. 291-304.

(1950[1895]) Projeto para uma psicologia científica. Edição Standard Brasileira de Obras Psicológicas Completas de Sigmund Freud. Rio de Janeiro: Imago, 1977. v. XXIII, p. 381-394.

JEANNEAU, A. (2002), L'hypocondrie ou le corps ailleurs qu' en lui-même. Revue française de Psychosomatique, 22, p. 199-138.

PRAGIER, G. (1995), Enjeux métapsychologiques de L'hypocondrie, L’hypocondrie, Paris, PUF, Monographies de la RFP, p. 73-90.

SEULIN, C. (2010), Unpoint de veu sur la dynamique des investisment dans l'hypocodrie, RFP, T.LXXIV, N 1, P. 217-226.

SMADJA, C. (2005). La vida operatória. Estudios Psicoanalíticos. C. Rolla y J. M. Franco Vicário (Trad.), Madrid: Editorial Biblioteca Nueva.

RACHE, E. (2018). Compulsão a Simbolização. Revista Brasileira de Psicanalise. São Paulo.

RACHE, E. TANIS, B. Roussilon na America Latina. Editora Edgar Blúcher, São Paulo.

ROUSSILLON, R. (1999) Agonie, clivage et symbolisation. Paris: Puf. Le plaisir et la répétition. Théorie du processus psychique. Paris: Dunod, 2001. Manuel de pratique clinique. Paris: Elsevier-Masson, 2012. 